\title{
SOJA Y MINERÍA: DOS LECTURAS TERRITORIALES EN LA ARGENTINA RECIENTE *
}

\author{
Recibido: 05 de octubre de 2017 • Aprobado: 05 de marzo de 2018 \\ DOI: $10.22395 /$ seec.v21n47a7
}

\author{
Silvia Gorenstein** \\ Jorge Hernández $z^{* * *}$ \\ Delia De La Torre ${ }^{* * * *}$
}

\section{RESUMEN}

Este trabajo analiza las dinámicas recientes de dos tipos de especializaciones en actividades intensivas en recursos naturales: una, de carácter agrícola, remite al complejo sojero; y la otra, a la minería metalífera. Con el auxilio de métodos cuantitativos se realizó una lectura estilizada sobre aquellos rasgos que ejercen influencia en los mercados de trabajo regionales y en las finanzas públicas provinciales, en la cual se exploraron encadenamientos productivos localizados, marcos regulatorios y políticas públicas nacionales. Los resultados muestran reconfiguraciones productivas que no han generado aumentos significativos en las estructuras locales de empleo, aunque sí alteraciones cualitativas considerables, a su vez que el efecto redistributivo territorial de los mecanismos fiscales de tributación ha tenido impactos diversos y distintos en los casos considerados.

\section{PALABRAS CLAVE}

Recursos naturales; agricultura; minería; mercado de trabajo; actividad económica regional; política pública; América Latina.

\section{CLASIFICACIÓN JEL}

O13; L71; Q17; R11

\section{CONTENIDO}

Introducción; 1. La agricultura pampeanizada: producción, exportaciones y trabajo; 2. La minería metalífera en San Juan: producción, exportaciones y trabajo; 3. Marcos regulatorios y políticas de particular impacto en las finanzas provinciales; 4. Conclusiones; Bibliografía.

\footnotetext{
En este artículo se presentan avances del proyecto de investigación: "Recursos naturales y nuevas territorialidades en la Argentina reciente", de la Agencia Nacional de Promoción Científica y Tecnológica.

* Economista, Universidad Nacional del Sur, Bahía Blanca, Argentina. Especialista en planificación regional y Posgrado en Desarrollo Económico y Planificación, Instituto Latinoamericano de Planificación Económica y Social (Ilpes/CepalNaciones Unidas), Santiago de Chile, Chile. Magíster en Economía, Universidad Nacional del Sur, Bahía Blanca, Argentina. Investigadora del Consejo Nacional de Investigaciones Científicas y Tecnológicas (Conicet); Centro de Estudios Urbanos y Regionales (CEUR-Conicet), Ciudad de Buenos Aires, Argentina. Miembro del Consejo Científico de la Red Iberoamericana de Investigadores en Globalización y Territorio (RII). Dirección: Lavalleja 50, $3^{\circ}$ C (CP1414), Buenos Aires, Argentina. Teléfono: 54114855 2718. Correo electrónico: silvia.gorenstein@gmail.com.

** Economista, Universidad Nacional de Río Cuarto, Río Cuarto, Argentina. Magíster en economía aplicada, orientación a la economía regional y urbana, Universidad Autónoma de Barcelona, Barcelona, España. Profesor asociado efectivo, Departamento Economía, Facultad de Ciencias Económicas, Universidad Nacional de Río Cuarto, Rio Cuarto, Argentina. Director de Programas y Proyectos de la UNRC, Grupo Responsable Proyectos ANPCyT. Dirección: Sarmiento 239 - 5800 Río Cuarto. Teléfono: 54358484055. Correo electrónico: jhernandez@eco.unrc.edu.ar.

**** Politóloga, Universidad Nacional de San Juan, San Juan, Argentina. Especialista en planificación regional, Instituto Latinoamericano de Planificación Económica y Social (Ilpes/Cepal - Naciones Unidas), Santiago de Chile, Chile. Máster en desarrollo económico en América Latina, Universidad Internacional de Andalucía, Andalucía, España. Docenteinvestigadora del Instituto de Investigaciones Socioeconómicas de la Facultad de Ciencias Sociales, Universidad Nacional de San Juan, Argentina. Dirección: Paula A. de Sarmiento 800-sur (5400). San Juan. Teléfono: 542644261637 . Correo electrónico: delatorre.delia@gmail.com.
} 


\title{
SOY AND MINING: TWO TERRITORIAL READINGS IN RECENT ARGENTINA
}

\begin{abstract}
This paper analyzes the recent dynamics of two types of specialization in natural resources-intensive activities: one, of an agricultural nature, refers to the soybean complex; and the other, to metal mining. With quantitative methods, a stylized reading was made about those features that influence regional labor markets and provincial public finances, in which localized productive chains, regulatory frameworks, and national public policies were explored The results show productive reconfigurations that have not generated significant increases in local employment structures, although they have caused considerable qualitative alterations, while the territorial redistributive effect of taxation mechanisms has had different impacts in the cases considered.
\end{abstract}

\section{KEYWORDS}

Natural resources; farming; mining; labor market; regional economic activity; Public politics; Latin America.

\section{JEL CLASSIFICATION}

O13; L71; O17; R11

\section{SOJA E MINERAÇÃO: DUAS LEITURAS TERRITORIAIS NA ARGENTINA RECENTE}

\section{RESUMO}

Este artigo analisa a dinâmica recente de dois tipos de especialização em atividades intensivas em recursos naturais: uma, de natureza agrícola, refere-se ao complexo de soja; e a outra, a mineração de metais. Com a ajuda de métodos quantitativos, foi feita uma leitura estilizada das características que influenciam os mercados de trabalho regionais e as finanças públicas provinciais, na qual foram exploradas ligações produtivas localizadas, marcos regulatórios e políticas públicas nacionais. Os resultados mostram reconfigurações produtivas que não geraram aumentos significativos nas estruturas locais de emprego, embora tenha ocorrido consideráveis alterações qualitativas, enquanto o efeito redistributivo territorial dos mecanismos de tributação teve impactos diversos e diferentes nos casos considerados.

\section{PALAVRAS-CHAVE}

Recursos naturais; agricultura; mineração; mercado de trabalho; atividade econômica regional; política pública; América Latina.

\section{CLASSIFICAÇÃO JEL}

O13, L71, Q17, R11.

\section{CONTEÚDO}

Introdução; 1. Agricultura pampeanizada: produção, exportação e trabalho; 2. Mineração de metais em San Juan: produção, exportação e trabalho; 3. Marcos regulatórios e políticas de impacto particular nas finanças provinciais; 4. Conclusões; Bibliografia. 
Soja y minería: dos lecturas territoriales en la Argentina reciente

\section{INTRODUCCIÓN}

Durante las últimas tres décadas se han trazado cambios en el mapa productivo del país, con la implantación de un nuevo complejo productivo (minería) y las profundas transformaciones que se produjeron en otros, también ligados a los recursos naturales (agroalimentarios, forestal, hidrocarburos). Aunque el Estado Nacional resignó parte del manejo de la riqueza natural', con su rol activo en la configuración del territorio ${ }^{2}$ se establecieron condiciones macroeconómicas generales (política cambiaria, fiscal, tributaria, etc.) que incidieron en esta reconfiguración productiva territorial. El escenario se completa con un dispositivo normativo que plasma, entre otros, un nuevo régimen de inversiones para la minería metalífera, la explotación de bosques y, también en la década pasada, los hidrocarburos y biocombustibles, que generaron las condiciones de atractividad para importantes jugadores globales en estos negocios.

Cambios tecnológicos y organizativos acompañaron este proceso e impulsaron transformaciones importantes en los complejos productivos de base agrícola -tanto en los típicos pampeanos como en los tradicionales de otras regiones (fruticultura; yerba mate, tabaco, etc.)-, lo que condujo a profundizar la concentración económica y el grado de internacionalización o exogeneidad decisoria, con consecuencias significativas en el funcionamiento de los mercados de trabajo territoriales. Estos temas son relevantes porque permiten indagar respecto de las nuevas perspectivas socioeconómicas, en ambientes y lugares diferentes, que se derivan de un modelo de desarrollo impulsado, en mayor medida, por el sector primario exportador (recursos naturales y commodities). Las tendencias a la reprimarización y su traducción en las dinámicas que exhiben complejos productivos globalizados (CPG) $)^{3}$, o sometidos a esta lógica, perfilan o profundizan dinámicas de acumulación diferenciadas al interior del país al combinarse con las condiciones naturales (ambiente y dotación de recursos naturales renovables y no renovables), la posición geográfica (accesibilidad, conectividad) y las trayectorias específicas de los territorios respectivos.

1 La Constitución Nacional de 1994 establece que "corresponde a las provincias el dominio originario de los recursos naturales existentes en su territorio". (Art. 124). Los estados provinciales conservan todo el poder no delegado al Gobierno Federal, así como aquel que se hubiesen reservado por medio de pactos especiales. La excepción la constituyen aquellos recursos que, de forma expresa, hubieran sido transferidos constitucionalmente a la Nación.

2 La inversión pública, que ha montado históricamente el sistema nacional de capital social básico (energía, transporte, telecomunicaciones, etc.), cumplió un rol significativo en la organización espacial del país y continúa engendrando efectos acumulativos que contribuyen a cristalizar cierta inercia locacional (económica y poblacional) en la Región Metropolitana de Buenos Aires y las cuatro provincias pampeanas (Gatto, 2013).

3 En el presente artículo se utiliza esta noción -CPG- a partir de una perspectiva teórica que combina la conceptualización de cadena global de valor y la tradicional de complejo productivo, utilizada para el sistema agroalimentario en etapas de economías nacionales con menor grado de apertura. 
Es precisamente esa línea de investigación la que se recorre en este artículo, cuyo objetivo principal radica en analizar las dinámicas contemporáneas que atraviesan a dos tipos diferentes de especializaciones en actividades intensivas en recursos naturales: una remite a un CPG de base agrícola, el de la soja; y la otra a la minería metalífera, que en particular tiene su desarrollo más reciente en la provincia de San Juan. En ambos casos se analizan evidencias sectoriales asociadas con dos aspectos que componen los potenciales efectos territoriales: trabajo y recursos fiscales. Para ello, se efectúa una lectura estilizada sobre aquellos rasgos que ejercen influencia en los mercados de trabajo regionales, a partir de combinar la visión de marcos regulatorios y políticas públicas nacionales (retenciones a las exportaciones, regalías) que tienen efectos territoriales redistributivos. Cabe aclarar que existen diferencias en las evidencias cuantitativas que se presentan para ambos casos, las cuales deben atribuirse, además de las de carácter sectorial, a la información secundaria disponible.

Cabe resaltar que, en el periodo 2003-2015, hubo importantes avances respecto de políticas de transferencia de renta, instrumentos de protección (asignación universal por hijo y universalización de la protección social jubilatoria a mayores de edad), crecimiento formal del empleo, valorización del salario mínimo y expansión del mercado interno de consumo, los cuales mejoraron las condiciones generales de los sistemas económicos locales/provinciales, pero ello excede los alcances del presente artículo. Con esto, nuestro análisis alude a los dos procesos productivos que pueden tomarse como ejemplos distintos por su particular incidencia provincial/nacional en el marco de un periodo de mayor alcance, en el cual se produjeron marcadas diferencias en la orientación de la política pública. La nueva dirección posneoliberalismo de la década de 1990- enfrentó entonces condiciones establecidas en marcos regulatorios anteriores, tal como se analiza aquí para el caso de la minería, y desde una mirada de largo plazo, transformaciones estructurales que se han desarrollado en el sistema agroalimentario globalizado (Gorenstein, 2016), y que, en mayor o menor medida, se traducen en el funcionamiento reciente de la agricultura pampeana con sus tendencias territoriales expansivas.

\section{LA AGRICULTURA PAMPEANIZADA: PRODUCCIÓN, EXPORTACIONES Y TRABAJO}

El modelo pampeano de agricultura extensiva, con amplio predominio de la soja desde fines de la década de 1990, se ha expandido hacia otras regiones, como Cuyo (provincia de San Luis), NEA (provincia del Chaco) y NOA (provincias de Salta, Tucumán y Santiago del Estero). En ese periodo, el valor promedio de las mejores tierras agrícolas del país, ubicadas en la región pampeana, experimentó un salto significativo, al igual que las tierras ubicadas en zonas extrapampeanas donde se produjo 
la expansión de la soja o, en el marco de este proceso, la intensificación de la ganadería (Gorenstein y Ortiz, 2016).

La tabla 1 permite apreciar dos tendencias divergentes en la territorialización de la CPG de la soja. Por un lado, la expansión extrapampeana en la producción y exportación de esta oleaginosa: si bien destaca la importancia de las provincias pampeanas en las exportaciones del complejo sojero, también ilustra su difusión en las provincias no tradicionales arriba mencionadas, las cuales, en conjunto, superan el $10 \%$ de las exportaciones de grano/poroto. Por otro lado, se observa una fuerte concentración del proceso de industrialización y exportación del biodiésel, con particular intensidad en la Provincia de Santa Fe, que explica el 76,1 \% del valor total de las ventas externas.

Tabla 1. Exportaciones de soja y biodiésel, año 2016

\begin{tabular}{|l|c|c|c|c|}
\cline { 2 - 5 } \multicolumn{1}{c|}{} & \multicolumn{3}{c|}{ Millones de dólares corrientes } & \multirow{2}{*}{$\begin{array}{c}\text { Participación } \\
\text { (porcentaje) }\end{array}$} \\
\cline { 2 - 5 } \multicolumn{1}{c|}{ Soja } & Biodiésel & Total & 29,9 \\
\hline Buenos Aires & $1.190,80$ & 145,6 & $1.336,40$ & 1,2 \\
\hline Chaco & 55,9 & & 55,9 & 25,4 \\
\hline Entre Ríos & 985,5 & 150,6 & $1.136,20$ & 3,2 \\
\hline La Pampa & 99,3 & & 141 & 2,2 \\
\hline Salta & 47,9 & & 99,3 & 1,1 \\
\hline San Luis & 67,6 & & 47,9 & 1,5 \\
\hline Santa Fe & 457,5 & 943,4 & $1.400,90$ & 31,3 \\
\hline S. del Estero & 137,4 & & 137,4 & 3,1 \\
\hline Tucumán & 36,2 & & 36,2 & 0,8 \\
\hline Indeterminado & 14,2 & & 14,2 & 0,3 \\
\hline Total & $3.233,30$ & $1.239,60$ & $4.472,90$ & 100,0 \\
\hline
\end{tabular}

Fuente: elaboración propia con datos de OPEX-Indec (2017).

En aras de expandir el contenido de bienes industrializados a partir del grano/ poroto, se presenta en la tabla 2 (véase también el mapa 1) la expresión territorial del CPG de la soja. A las exportaciones de biodiesel (U\$ 1.240 millones) se suman U\$ 9.970 millones de subproductos oleaginosos de soja (expellers, harinas y pellets) y 
los más de U\$ 4.100 millones de aceite de ese grano, con lo que se obtiene el valor registrado de bienes industrializados de ese origen exportados en 2016.

Tabla 2. Exportaciones del complejo de la soja, año 2016

\begin{tabular}{|l|c|c|c|c|c|c|}
\cline { 2 - 7 } \multicolumn{1}{l|}{} & Grano (U\$) & $\begin{array}{c}\text { Participación } \\
\text { (porcentaje) }\end{array}$ & $\begin{array}{c}\text { Industrializados } \\
\text { (U\$) }\end{array}$ & $\begin{array}{c}\text { Participación } \\
\text { (porcentaje) }\end{array}$ & Total (U\$) ${ }^{*}$ & $\begin{array}{c}\text { Participación } \\
\text { (porcentaje) }\end{array}$ \\
\hline Buenos Aires & $1.190,80$ & 36,8 & $2.200,70$ & 14,4 & $3.391,50$ & 18,3 \\
\hline Chaco & 55,9 & 1,7 & & & 55,9 & 0,3 \\
\hline Córdoba & 985,5 & 30,5 & $2.979,60$ & 19,5 & $3.965,10$ & 21,4 \\
\hline Entre Ríos & 141 & 4,4 & & & 141 & 0,8 \\
\hline La Pampa & 99,3 & 3,1 & & & 99,3 & 0,5 \\
\hline Salta & 47,9 & 1,5 & & & 47,9 & 0,3 \\
\hline San Luis & 67,6 & 2,1 & & & 67,6 & 0,4 \\
\hline Santa Fe & 457,5 & 14,2 & $10.002,00$ & 65,3 & $10.459,50$ & 56,4 \\
\hline S. del Estero & 137,4 & 4,3 & 0 & 0 & 137,5 & 0,7 \\
\hline Tucumán & 36,2 & 1,1 & & & 36,2 & 0,2 \\
\hline Indeterminado & 14,2 & 0,4 & 133,7 & 0,9 & 147,9 & 0,8 \\
\hline Total & $\mathbf{3 . 2 3 3 , 3 0}$ & $\mathbf{1 0 0}$ & $\mathbf{1 5 . 3 1 6 , 0 0}$ & $\mathbf{1 0 0}$ & $\mathbf{1 8 . 5 4 9 , 3 0}$ & $\mathbf{1 0 0}$ \\
\hline
\end{tabular}

* Millones de dólares estadounidenses corrientes.

Fuente: elaboración propia con datos de OPEX-Indec (2017).

La tabla anterior refleja que más del 80 \% de las exportaciones del complejo sojero son bienes con algún nivel de procesamiento que se originan casi en su totalidad en tres provincias, con fuerte participación de Santa Fe. Es allí donde se rentabilizan las mayores economías de localización definidas por la presencia de los puertos del Gran Rosario en el río Paraná - desde la localidad de Timbúes hasta Arroyo Seco-, con instalaciones de almacenamiento y molienda de las principales firmas del agronegocio (entre ellas tres de las transnacionales conocidas en el ámbito internacional como las $\mathrm{ABCD})^{4}$; y una red de infraestructura vial que permite la convergencia de la producción primaria en el lugar y facilita la salida transfronteriza de la producción. Estos factores locacionales, más la notable estructura concen-

\footnotetext{
4 Bunge, Cargill y Louis Dreyfus, sumado a la Aceitera General Deheza del grupo nacional Urquiza y al grupo suizo Glencore (Vidosa, 2017).
} 
trada del capital en la producción de aceite y biodiesel, definen el patrón de distribución territorial observado.

El biodiésel constituye la novedad del periodo reciente e involucra una ampliación de la demanda para los productos agrícolas (aceites de soja, maíz, colza, girasol, palma, canola, grasas animales, entre otros). Argentina participa del mercado mundial como uno de los principales productores de biodiésel a base de aceite de soja ; y al igual que en la molienda de grano y su comercialización, predominan los grandes actores económicos, que a partir del 2008 realizaron inversiones en plantas de biodiesel. ${ }^{6}$ Cabe subrayar que este fenómeno obedece a la combinación de varios factores: aumento de la demanda internacional (en mayor medida por la incidencia de las compras de China); implementación del Programa Nacional de Biocombustible que, a través de la Ley 26093 y el Decreto 109/07, posibilitó la mezcla obligatoria del gasoil con biodiésel; y la diferencia en las retenciones a la exportación que, en ese periodo, eran del $24 \%$ para el aceite y harina de soja, y de solo 2,5\% para el biocombustible considerado. Se volverá al tema de las retenciones más adelante.

La llamada 'sojización' implicó, tal como se dijo, la ocupación de nuevas tierras, además de la reconversión de superficies agrícolas con tradición en otros cultivos y en actividades pecuarias. Se disparan así una serie de problemáticas rurales que comprenden desde la dimensión ambiental (nuevos riesgos por el uso intensivo de las tierras y fertilizantes, contaminación hídrica y desertificación de agrosistemas, entre los más importantes) hasta las profundas redefiniciones en su estructura social. En definitiva, se trata de un proceso de expansión-ocupación de superficies cultivables vinculado al funcionamiento del agronegocio en gran escala que, de manera casi homogénea, se expresa a través $\mathrm{de}^{7}$ :

- Los pools de siembra, modalidad difundida desde el agro pampeano a las otras realidades agrarias extrapampeanas -y en años más recientes, a países vecinos-, que combinan la propiedad de la tierra, muchas veces a través de fideicomisos, con el arrendamiento $u$ otros arreglos de financiamiento y alianzas transitorias que viabilizan su acceso y explotación extensiva. En definitiva, se trata de una

5 El país tuvo una evolución positiva en este sentido hasta 2012, momento en que un conjunto de factores -régimen impositivo local y políticas antidumping por parte de la Unión Europea, entre otros- provocaron una reducción de la producción industrial; así entonces, Argentina perdió la posición en el mercado mundial en 2013 y fue superada por Estados Unidos. Hacia 2014 recuperó el primer lugar, sobrepasando a Brasil y Estados Unidos.

6 La industria de biodiésel está conformada por 35 empresas productoras y 7 comercializadoras; el $15 \%$ de las empresas que conforman el sector (LDC S.A., T6 Ingeniería S.A. y Renova S.A.) poseen la mitad de la capacidad instalada de todo el mercado (Donadoni et al., 2017, p. 4).

7 Para un análisis pormenorizado de los nuevos y "viejos" actores que intervienen en la estructura del agronegocio nacional, veánse Flichman (1978), Domínguez (2016) y Arceo (2003; 2010), entre otros. 
estrategia organizacional para alcanzar la escala económica que optimiza el uso del nuevo paquete tecnológico (en particular, soja transgénica e insumos asociados) y diversifica riesgos de producción (clima, suelos, etc.) ${ }^{8}$.

- El proceso de internacionalización/transnacionalización de los grandes pools de origen local que realizan operaciones a corto plazo (arrendamientos de grandes extensiones por ciclos productivos) y adquisiciones conjuntas (joint venture). Se trata de los principales pools de origen nacional -Los Grobo, el Tejar y MSUque, además de invertir en tierras de cultivo, nacionales y de países vecinos, han profundizado el control que ejercen en ciertas cadenas agroalimentarias, desplegando para ello estrategias de inversión hacia adelante y hacia atrás (logística, plantas de primera transformación, etc.) ${ }^{9}$.

- La difusión generalizada de la figura del contratista, en la cual los productores (desde los grandes, medianos y pequeños familiares hasta los que operan como gerentes de grandes pools) terciarizan diferentes demandas durante el ciclo de producción (maquinaria y equipamiento, servicios tecnológicos, mano de obra, e incluso la gestión completa del proceso de producción $)^{10}$. Ello puede combinarse también con la capitalización y especialización de las actividades, lo que contribuye a elevar la eficiencia agraria y a conformar otro sujeto socioeconómico -el contratista productor- quien, junto a la atención de su explotación, realiza servicios a terceros, en general ubicados en zonas próximas a la misma.

Ahora bien, ¿̇cuál es la incidencia cuantitativa del complejo sojero en los mercados de trabajo nacional/provinciales?

Para empezar, no hay consenso respecto a las cifras, ni sobre la tendencia de las últimas décadas y las metodologías del cálculo. Por ejemplo, el estudio de Bisang y Sztulwark (2007), que estimó entre 200.000 y 300.000 ocupados en todo el país para el ciclo 2003-2004 y contempla todos los eslabones de la cadena, es cuestionado porque incurriría en sumar puestos de diferentes actividades, con el consecuente doble conteo de los referidos a la soja. En cambio, el Centro de Investigación y Formación de la República Argentina (Cifra) se concentra en el eslabón primario con

8 En la conformación del pool intervienen fideicomisos que pueden estar integrados por inversores extrasectoriales (bancos, financieras, profesionales urbanos, etc.), incluyendo empresas de servicios y asesoramiento, proveedores de insumos, empresas acopiadoras y comercializadoras. En los de menor tamaño, suelen darse arreglos informales entre el propietario de la explotación agropecuaria, el dueño de la maquinaria (contratista) y un proveedor de asesoramiento tecnológico.

9 Un análisis sobre las estrategias y alianzas de estos grupos se realiza en Gorenstein y Ortiz (2016).

10 Las empresas contratistas de servicios suelen localizarse en las zonas de producción para pasar unos 3 o 4 meses realizando cosechas de granos finos y gruesos, incluidos los trabajadores contratados (Lódola y Fosatti, 2004). 
indicadores del sector agropecuario en su conjunto y señala que, mientras el valor agregado generado subió un 44,2 \% en el periodo 2002-2010, los puestos de trabajo solo crecieron en un $7 \%$, con una elasticidad-empleo producto promedio del 0,18 (Cifra, 2011). Otros autores constatan caídas en el volumen absoluto de ocupación permanente -un 30 \% según Neiman (2010) - y cambios en los requerimientos laborales (mano de obra más calificada) asociados a la siembra directa (Vidosa, 2017).

En segundo lugar, diversas investigaciones (Gorenstein et al. 2012; Neiman, 2010, entre otros) sobre los mercados rurales de trabajo advierten sobre los cambios cuanti y cualitativos derivados del nuevo paquete tecnológico (no solo en la soja), que se expresan en:

- Desplazamiento de la fuerza de trabajo (familiar, asalariada), acortamiento de los tiempos de trabajo y cambios en la relación laboral, lo cual conduce a intensificar la tendencia del contrato de mano de obra temporal (migrantes o empleados de los contratistas). Estas dinámicas atraviesan a todos los cultivos pampeanos (soja, girasol, maíz, trigo y maní) tras las innovaciones incorporadas.

- Movilidad intra e interregional asociada a la separación o división de la migración laboral y de los contratistas en dos etapas, relacionadas con los periodos de la cosecha de cereales (desde fines de la primavera hasta comienzos del verano) y la de oleaginosas (durante el otoño), sumada a la expansión de estas producciones hacia provincias extrapampeanas cuya estacionalidad varía de forma leve.

Por último, frente a una tendencia sostenida y estructural de reducción de la demanda de trabajo provocada por el avance de nuevos paquetes tecnológicos, se profundizan las condiciones de transitoriedad, precariedad y escasa formalización en el marco de esquemas de tercerización que intermedian las relaciones laborales. Los territorios locales-regionales donde se despliegan estos complejos productivos son los escenarios en los cuales se expresan estos cambios que, desde una dimensión más general, involucran los medios rural y urbano ${ }^{11}$.

\section{LA MINERÍA METALÍFERA EN SAN JUAN: PRODUCCIÓN, EXPORTACIONES Y TRABAJO}

En términos generales puede hablarse de dos grandes divisiones entre las líneas argumentales en torno a la minería y sus efectos (favorables o no) en términos económicos, sociales, ambientales, etc. la que proviene de la literatura sectorial, con

"El consenso teórico en torno a las dinámicas vinculadas con la "nueva ruralidad" (solapamiento entre lo rural y lo urbano, importancia creciente de la economía rural no agrícola, pluriactividad o multiocupación de los residentes rurales, etc.) fundamenta la consideración de que la residencia en el medio rural y la ocupación en el sector agropecuario pueden no presentarse de forma simultánea. 
aportes de las disciplinas ingenieriles y empresariales, que avalan repercusiones virtuosas (ingresos, empleo, divisas, etc.) y con argumentos opuestos a las conocidas percepciones sociopolíticas sobre sus efectos nocivos sobre los ecosistemas; y la contaminación ambiental' ${ }^{12}$. En cambio, desde la literatura económica y, en particular, desde el campo crítico de las ciencias sociales, más allá de la cuestión socioambiental, se plantea cierto consenso en torno a sus características de enclave. En este marco, y sobre todo en el periodo contemporáneo, se observa que tanto la minería como otras industrias extractivas son cada vez más intensivas en capital, con lo cual se ha aminorado aún más el efecto empleo que generan.

La reciente implantación de la gran minería en Argentina implicó una corriente de inversión extranjera directa (IED); si bien esta fue inferior a la de otros sectores, resultó significativa para la Provincia de San Juan y otros territorios. La tabla 3 muestra el mayor flujo en 2012 por el aumento de 47 nuevos proyectos mineros en el país (Argentina Minera, 2013).

Tabla 3. Minería: participación en el stock de IED en Argentina (2010-2014)

\begin{tabular}{|l|c|c|c|c|c|c|c|}
\hline \multirow{2}{*}{ Sector } & 2010 & 2011 & 2012 & 2013 & 2014 & $\begin{array}{c}\text { Variación } \\
2014 / 10\end{array}$ & $\begin{array}{c}\text { Contribución a la variación } \\
\text { de stock 2014/10 }\end{array}$ \\
\cline { 2 - 8 } & US* & U\$* & U\$* & U\$* & U\$* & $\%$ & $\%$ \\
\hline Minería & 5.668 & 6.767 & 10.964 & 5.931 & 5.797 & 2,3 & 3 \\
\hline Total IED & 87.108 & 93.844 & 101.073 & 90.482 & 91.132 & 4,6 & \\
\hline Minería sobre total & $7 \%$ & $7 \%$ & $11 \%$ & $7 \%$ & $6 \%$ & & \\
\hline
\end{tabular}

* Millones de dólares estadounidenses corrientes.

Fuente: Elaboración propia con información del BCRA (2017).

De esas inversiones de firmas transnacionales que operan a escala global, San Juan recibió a Barrick Gold Corp ${ }^{13}$ (empresa con una participación del 9,5 \% de la producción mundial), que produce la mina Veladero, y al proyecto binacional -con Chile- de Pascua-Lama que, junto a otras empresas de menor cuantía, configuran el nuevo territorio minero (tabla 4 y mapa 1).

12 Básicamente se plantea que los emprendimientos actuales han incorporado nuevas tecnologías que mejoran sustantivamente las "viejas" prácticas de extracción.

13 Según la última información disponible, los principales accionistas son: Capital World Investors, Fidelity Management \& Research, Blackrock, NWO Investment Management, Tradewinds Global Investors, Banco Barclays (fondos de inversión y bancos de inversión con el 52 \% del paquete accionario). 
Soja y minería: dos lecturas territoriales en la Argentina reciente

Tabla 4. Emprendimientos mineros metalíferos y origen del capital en la Provincia de San Juan

\begin{tabular}{|l|l|l|l|l|l|}
\hline \multicolumn{1}{|c|}{ Emprendimiento } & \multicolumn{1}{|c|}{ Empresa } & $\begin{array}{l}\text { Origen del } \\
\text { capital y capital } \\
\text { accionarios }\end{array}$ & $\begin{array}{l}\text { Minerales } \\
\text { extraídos }\end{array}$ & \multicolumn{1}{|c|}{ Localización } & $\begin{array}{c}\text { Tipo de } \\
\text { explotación }\end{array}$ \\
\hline $\begin{array}{l}\text { Veladero (2004) } \\
\text { y Lama-Pascua } \\
(2013)\end{array}$ & Barrik Gold & $\begin{array}{l}\text { Canadiense. } \\
\text { Grupos de in- } \\
\text { versión* }\end{array}$ & Oro, plata & $\begin{array}{l}\text { Departamento } \\
\text { de Iglesia }\end{array}$ & $\begin{array}{l}\text { A cielo abier } \\
\text { to }\end{array}$ \\
\hline $\begin{array}{l}\text { Gualcamayo } \\
(2009)\end{array}$ & $\begin{array}{l}\text { Yamana Gold-Mi- } \\
\text { nas Argentinas }\end{array}$ & Canadiense & Oro & $\begin{array}{l}\text { Departamento } \\
\text { de Jáchal }\end{array}$ & $\begin{array}{l}\text { A cielo abier- } \\
\text { to }\end{array}$ \\
\hline Casposo (2011) & Troy Resources & $\begin{array}{l}\text { Canadien- } \\
\text { se-australia- } \\
\text { no** }\end{array}$ & Oro y Plata & $\begin{array}{l}\text { Departamento } \\
\text { de Calingasta }\end{array}$ & $\begin{array}{l}\text { Actualmente } \\
\text { subterránea }\end{array}$ \\
\hline
\end{tabular}

** Empresa que cotiza en bolsa de pequeño tamaño.

Fuente: elaboración propia con información de las páginas web de las empresas (2017).

En el marco de esta dinámica se produjeron cifras récord en la producción de oro y plata con destino principal a Canadá, país de origen de Barrick, el mayor operador de oro en San Juan. Entre 2007 y 2014, este metal tuvo una tasa de crecimiento del $268 \%$, a pesar de la caída desde 2011. Así, durante el periodo 2003-2010, la provincia pasó de aportar el 0,5\% de las exportaciones totales nacionales al 3,1 \% (con un 2,2 \% en 2016), a medida que un sector inexistente al comienzo de la década pasó a representar el 75 \% promedio de sus exportaciones.

Para San Juan, el cambio fue sustantivo: en primer lugar, el valor de las ventas externas más que se duplica a partir del funcionamiento de las minas (tabla 5) y, a su vez, el peso de estas exportaciones, aunque oscilante, desplaza de manera amplia a las tradicionales ${ }^{14}$. En segundo lugar, el proceso de reespecialización basado en nuevos commodities suma vulnerabilidad a la economía sanjuanina, asociada a las fluctuantes variaciones del precio internacional del oro y la plata.

Otra de las repercusiones sectoriales por contemplarse alude al mercado de trabajo ${ }^{15}$. Entre el primer trimestre de 2010 e igual periodo de 2015, la ocupación nacional en la minería metalífera creció a una tasa anual acumulativa del 6,9\%, por encima del 1,9\% que representó la media del empleo registrado nacional y del 1,2 \%

14 En el año 2000, el $58 \%$ de sus ventas externas estaba comprendido por productos vitícolas, hortícolas y olivícolas; mientras que en el 2015, estas descendieron al $19 \%$.

15 La aparición de un nuevo sector de inserción internacional, que impulsa cambios en las bases de exportación de las provincias donde las inversiones se localizan y consolidan (Catamarca, San Juan, Santa Cruz, otros proyectos mineros), también incide en otros indicadores (PBI, encadenamientos, etc.) que aquí no están contemplados. 
del resto de la actividad minera. Pero, a pesar de esos incrementos, los puestos de trabajo creados son relativamente bajos, dado el uso intensivo de capital. Los 10.956 asalariados registrados en el sector metalífero en el primer trimestre de 2015 son apenas el 0,17\% del empleo nacional ${ }^{16}$. En este sentido, se argumenta que el empleo indirecto es mucho más significativo: "por cada empleo generado en la nómina de una empresa minera, las mismas requieren la generación de 2 puestos de trabajo adicionales en empresas proveedoras y contratistas" (Cámara Argentina de Empresarios Mineros - CAEM, 2012, p. 55). Siguiendo esta fuente, la actividad minera metalífera daba cuenta de 10.866 empleos, los contratistas 8396 y los "indirectos puros" 16.432, lo que totaliza entonces 34.439 ocupados vinculados a la actividad en el 2015 (CAEM, 2016, p. 27).

Tabla 5. Exportaciones de la Provincia de San Juan por productos

\begin{tabular}{|l|c|c|c|c|}
\hline & 2002 & 2005 & 2007 & 2014 \\
\hline Total exportaciones & U\$* & U\$* & U\$* & U\$S* \\
\hline Piedras y metales preciosos (oro y plata) & 140 & 274 & 726 & 1739 \\
\hline Vinos & 8 & 0 & 337 & 1240 \\
\hline Mostos & 12 & 52 & 74 & 71 \\
\hline Plata & 0 & 0 & 0 & 52 \\
\hline Pasas de uva & 11 & 25 & 34 & 36 \\
\hline Cal viva & 4 & 9 & 14 & 32 \\
\hline Uva fresca & 28 & 41 & 53 & 28 \\
\hline Aceite de oliva & 3 & 8 & 9 & 5 \\
\hline
\end{tabular}

* Valor FOB en millones de dólares estadounidenses corrientes.

Fuente: elaboración propia con IIEE, San Juan (2017).

Por último, los asalariados registrados del sector de extracción de metales perciben un salario medio que es superior al promedio nacional y al del resto de la minería. En 2015, la remuneración promedio en la extracción metalífera alcanzó los 39.624 pesos corrientes, un $160 \%$ por encima del promedio del sector privado en su conjunto (\$15.269) y un $120 \%$ superior al del resto de las minas y canteras $(\$ 18.008)^{17}$.

\footnotetext{
16 Se considera información del Observatorio de Empleo y Dinámica Empresarial, MTEySS con base en SIPA y del Ministerio de Hacienda y Finanzas de la Nación (2016), respectivamente.

17 Información del Ministerio de Hacienda y Finanzas de la Nación (2016).
} 
Visto desde la perspectiva territorial, es precisamente este último aspecto el que opera como un importante factor de legitimación de la actividad, sumado a la intensidad del efecto empleo que se genera durante la etapa de instalación, como ocurre con otros proyectos de envergadura (hidrocarburos; usinas hidroeléctricas, etc.). En la construcción de la mina Veladero (2003), por ejemplo, se ocuparon unos 3.800 trabajadores y para el proyecto Pascua Lama (que comenzó en 2009) se llegaron a demandar alrededor de 10.000 puestos de empleo ${ }^{18}$. Esta tendencia se percibe de forma muy manifiesta en el sector de la construcción, que pasó de absorber 1694 trabajadores en 2003 a 17.791 en 2013, y la cifra cayó a 12.857 en 2014.

La intensidad en el empleo se aminora con la puesta en marcha de los proyectos mineros (véase la tabla 6). En efecto, esta actividad es una de las de menor participación en la estructura laboral provincial: las empresas vinculadas a la rama de minas y canteras (incluidas las no metalíferas) absorbían solo el 3,8 \% del empleo local en el primer trimestre del 2016, lo que equivale a menos del $2 \%$ de la población económicamente activa (PEA) de San Juan; mientras que la agricultura en su conjunto alcanzaba el 10 \% de dicho indicador laboral (Observatorio de Empleo y Dinámica Empresarial).

Hay tres factores que se distinguen en las variables ocupacionales de la minería provincial. El primero es el salario: como se mencionó, la minería paga los salarios más altos en el contexto de un mercado laboral en el cual las remuneraciones promedio de la otra actividad primaria de especialización en la provincia -agricultura- apenas alcanzan un $16 \%$ de las que se perciben en la industria extractiva. El segundo corresponde al factor empleo registrado, que es mayoritario en esta actividad y con una tendencia creciente desde 2006, cuando Veladero comenzó a producir. El tercero, sin embargo, advierte sobre los riesgos y vulnerabilidad de una economía provincial poco diversificada y vinculada a un par de commodities. En este caso, las fluctuaciones están muy atadas al comportamiento internacional del precio del oro, hecho que marca la vulnerabilidad asociada a las llamadas regiones commodities $^{19}$ (Daher, 2003).

18 Desde 2013, el proyecto de carácter binacional con Chile está suspendido, y han quedado cesantes los ocupados en su construcción.

19 En un análisis reciente sobre territorios chilenos tradicionalmente especializados en la minería, Daher et al. (2017, p. 16) señalan: "La minería es un sector menos intensivo en trabajo directo. A pesar de ello, los efectos laborales del fin del súper ciclo del cobre son, aunque diversos en el tiempo y en el espacio, especialmente significativos: el efecto-empleo del fin del súper ciclo del cobre se manifiesta más tardiamente que el efecto-PIB, y, con fluctuaciones, se acusa más en las regiones más especializadas en minería y, singularmente, en pequeña y mediana minería (menos competitiva y más intensiva en trabajo)". 
Mapa 1. Argentina: provincias exportadoras del complejo sojero y yacimientos mineros en la Provincia de San Juan, año 2016

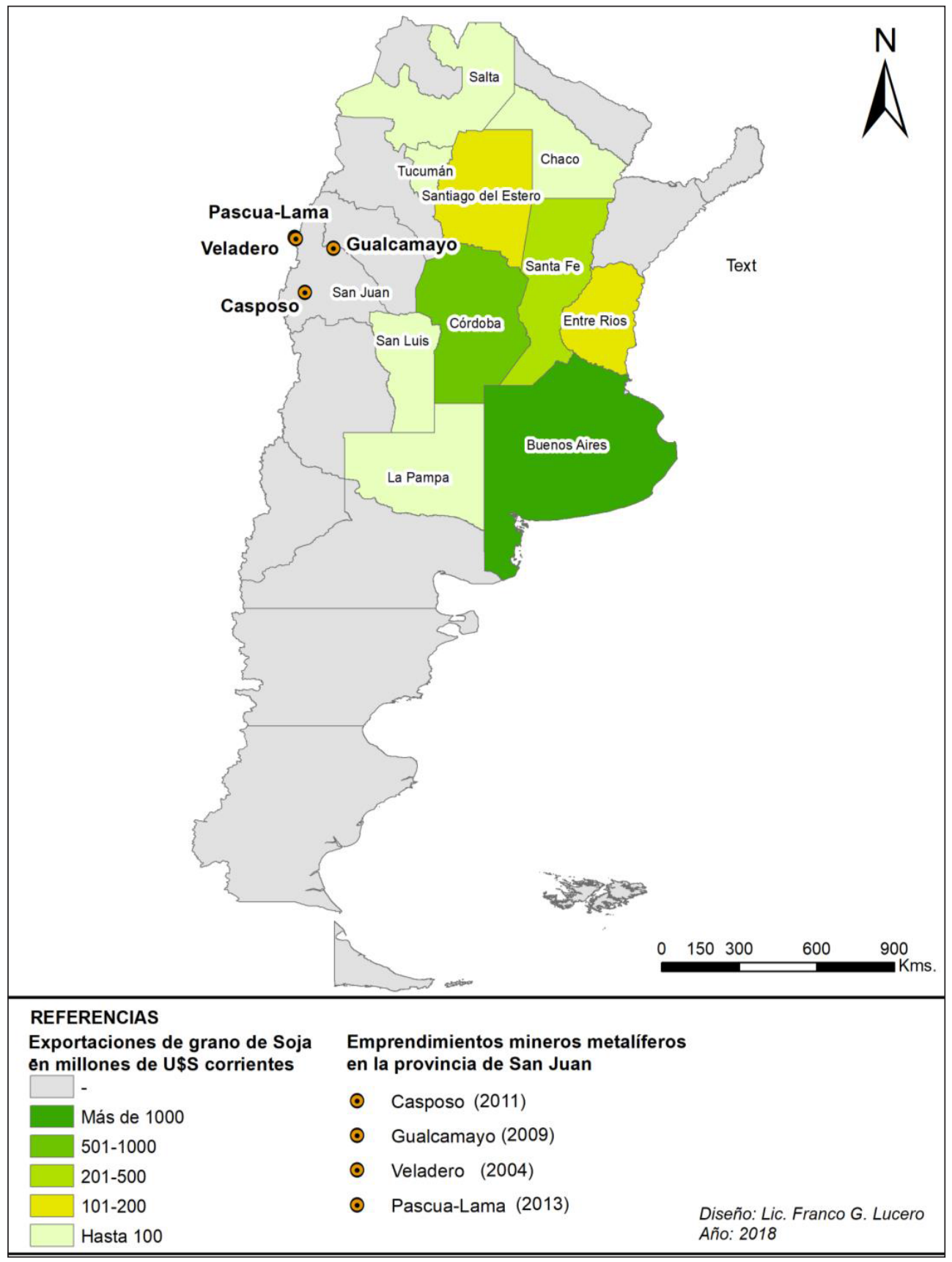

Fuente: elaboración propia con datos de OPEX-Indec e información de las páginas web de las empresas (2017). 
Soja y minería: dos lecturas territoriales en la Argentina reciente

Tabla 6. Empleo registrado en el sector de la minería metalífera en la Provincia de San Juan.

\begin{tabular}{|l|l|}
\hline Año & Empleo \\
\hline 2006 & 1.068 \\
\hline 2007 & 1.239 \\
\hline 2008 & 1.517 \\
\hline 2009 & 1.788 \\
\hline 2010 & 2.000 \\
\hline 2011 & 2.277 \\
\hline 2012 & 2.423 \\
\hline 2013 & 2.582 \\
\hline 2014 & 2.641 \\
\hline 2015 & 2.729 \\
\hline
\end{tabular}

Fuente: Indec (2017).

\section{MARCOS REGULATORIOS Y POLITICAS DE PARTICULAR IMPACTO EN LAS FINANZAS PROVINCIALES}

\subsection{Regulaciones para la minería}

En el periodo del gobierno menemista (1989-1999) se produjeron transformaciones importantes en el marco regulatorio de la minería. El Pacto Federal Minero (1993), en el cual se acordó el manejo por parte de las provincias con recursos mineros, quedaría plasmado en el artículo 124 de la Constitución de $1994^{20}$. De forma paralela, en 1993 se dictaron las leyes 24.196 de Inversiones Mineras, 24.224 de Reordenamiento Minero y, posteriormente, la 24.585/95 de Protección Ambiental para la Actividad Minera. La primera de ellas establece la promoción de la actividad con beneficios fiscales e impositivos para la prospección, exploración, desarrollo, preparación y extracción de sustancias minerales. Entre ellos se encuentra la estabilidad fiscal por 30 años, con lo cual, a partir de la aprobación del proyecto, el gobierno

20 La participación en la captación de una parte de la renta por parte de los territorios donde operan las industrias extractivas suele justificarse con dos argumentos; i), la necesidad de compensar las repercusiones negativas de naturaleza socioambiental y otras externalidades del mismo signo; y ii), la descentralización de la capacidad de gasto público (federalismo fiscal) y sus ventajas por una mayor adaptación a las necesidades de los ciudadanos y de la economía local. Respecto al reparto territorial de los recursos públicos por la vía fiscal, sin embargo, suelen presentarse objeciones relacionadas a los riesgos que implica la volatilidad de los fondos transferidos, particularmente en los casos donde existe una fuerte dependencia de estos últimos. 
no podrá modificar ninguna carga impositiva. Otro artículo establece la capacidad de desgravar del impuesto a las ganancias los gastos de exploración y prospección, y los referidos a las inversiones en maquinarias y equipos, infraestructura y construcciones en la etapa de puesta en marcha de la explotación. En esta ley también se establece que las regalías por pagar no pueden exceder el $3 \%$ del valor de "boca de mina", según la declaración de las empresas.

La Ley de Reordenamiento Minero, por su parte, aborda aspectos sobre las cartas geológicas del territorio nacional, lo mismo que sobre la institucionalización del Consejo Federal de Minería y del Canon Minero; en este sentido, la Ley de Protección Ambiental fue incluida posteriormente en el Código de Minería y, por lo tanto, regula los aspectos ambientales del sector en todo el territorio nacional, con generalidades sobre el cuidado del medio ambiente ${ }^{21}$. En concordancia con lo anterior, la Provincia de San Juan sancionó la Ley 4771/80 con un régimen de exenciones impositivas para el sector, y el Código Tributario establece la exención de los impuestos a los ingresos brutos y al sello22.

A partir de 2008, durante el gobierno de Néstor Kirchner, se estableció el cobro de retenciones a la minería; esta medida fue anulada por el Decreto PEN n. 349 del gobierno de Mauricio Macri, sancionado a principios de 2016. Un instrumento complementario creado por la gestión del kirchnerismo -los fideicomisos minerosintrodujo otro efecto descentralizador por la vía de las inversiones públicas locales (municipales) que se autorizan para las localidades donde se emplazan las minas, y que van por fuera de las que provienen por captación de regalías. Se conformaban con los aportes del $1 \%$ de la facturación bruta durante los dos primeros años

${ }^{21}$ El Tratado sobre Integración y Complementación Minera entre Argentina y Chile (1999) que facilita la implementación de proyectos fronterizos entre ambos países dio lugar al proyecto Pascua-Lama que queda suspendida en 2013 por un conflicto ambiental en el vecino país.

22 Es interesante comparar este marco normativo con el tipo de lineamientos que existía mucho antes de que la minería se convirtiera en un gran negocio internacionalizado. En el año 1959 se creó, por medio de la Ley 14.771, Yacimientos Mineros de Agua de Dionisio (YMAD), con el objeto de realizar el cateo, exploración y explotación de los minerales en la zona minera de Agua de Dionisio - Catamarca (Bajo de la Alumbrera), empresa interestatal compuesta por la Provincia de Catamarca y la Universidad Nacional de Tucumán, descubridora del yacimiento por el doctor Abel Peirano, que lo donó a dicha institución. En ese momento, tuvo una fuerte inversión inicial del gobierno nacional. En el artículo 18 se establecen criterios para la distribución de sus utilidades líquidas y realizadas: 60 \% a la provincia de Catamarca; 40 \% para la terminación de la ciudad universitaria; y una vez concluida, el 50 \% a la Universidad Nacional de Tucumán y 50 \% restante a la formación de un fondo nacional que sería distribuido entre las demás universidades del Estado. Pero, en 1998, este escenario se transformó de manera sustancial: se conformó una Unión Transitoria de Empresas para su explotación, formada por tres mineras extranjeras -la compañía suiza XstrataPlc, Goldcorp y Yamana Gold (Canadá)- que perciben el $80 \%$ de las utilidades; el $20 \%$ restante se distribuye en un $60 \%$ a la provincia y un $20 \%$ a la UNT; y el otro $20 \%$ se distribuye a las Universidades nacionales (0,04\% de las ganancias de la Alumbrera). 
de producción; y a partir de ese momento, el tributo se incrementó al 1,5%por el mismo concepto.

Este tipo de retribución, a menudo no contemplada en la literatura crítica, también alimenta percepciones sociales y políticas (locales/provinciales) favorables a la minería. A priori, podría argumentarse que se produce cierta complementariedad con el accionar derivado de las estrategias de responsabilidad social empresarial desplegadas por las firmas mineras en estos territorios.

\subsubsection{Las regalías}

En la literatura económica hay numerosas contribuciones, de vieja y nueva data, que han abordado la cuestión de las industrias extractivas y sus repercusiones socioeconómicas. Como lo apunta Aguirre Unceta (2017), quien retoma a Hirschman (1958; 1977), la vía fiscal es la principal fuente de potenciales efectos favorables por parte de las actividades del sector extractivo, dado que sus conexiones con los otros sectores de una economía nacional tienden a ser escasas, al menos en su etapa inicial.

Para lo anterior se requiere que la captación pública de la renta generada por estas actividades refleje una adecuada relación con las ganancias, en particular si estas últimas son operadas por empresas transnacionales. Otro requerimiento alude a la gestión eficaz de los ingresos públicos extractivos, entendida en términos de beneficios sociales colectivos; ello supone evitar el escenario de rentseeking e ineficiencia publica -también nombrado por Hirschman-y, a su vez, por las tesis de la "maldición de los recursos naturales" sostenida por numerosos trabajos en este campo 23 .

Al respecto, las evidencias que presenta Basualdo (2012) en el caso de la Barrick Gold ponen en perspectiva el impacto de las regalías aplicadas a la actividad a partir del 2008.

Respecto de lo anterior, el autor nombrado afirma lo siguiente sobre el año 2007 (recién iniciadas las actividades extractivas): "las utilidades fueron de 75 millones de dólares, la tasa de ganancia fue del 25,8 \%. Sin embargo, la tendencia registrada en los años subsiguientes presenta un empinado crecimiento tanto de las utilidades como de las ventas y la rentabilidad empresaria". Sobre el año siguiente señala que "la tasa de ganancia fue del 28,9 \% en tanto las utilidades ascendieron a los 135 millones de dólares, el 60 \% de las cuales se explica como resultado de los ingresos generados por la renta aurífera" (Basualdo, 2012, p. 17).

23 Para una revisión actualizada sobre esta literatura teórica, veánse Altomonte y Sánchez (2016), y Aguirre Unceta (2017). 
En este marco, la percepción de San Juan en concepto de regalías aumentó un $113 \%$ durante el periodo 2008-2016. No obstante, su incidencia en el total de los ingresos tributarios provinciales osciló entre un 4,4 \% (en 2012, dada el alza del precio internacional del oro, que llegó a 1710 dólares por onza) ${ }^{24}$ y un 1,9\%, y valores promedios que no alcanzan el $3 \%$ de los gastos efectivizados por la provincia. La relación entre la captación por regalías y la coparticipación federal de impuestos -que oscila entre 3,8 \% y $8 \%$-también relativiza el efecto fiscal provincial de las mismas (tablas 7 y 8 ).

Tabla 7. Relación entre regalías, recursos provinciales tributarios e ingresos corrientes

\begin{tabular}{|c|c|c|c|c|c|}
\hline \multirow{2}{*}{ Años } & Regalías & $\begin{array}{c}\text { Totales recursos } \\
\text { tributarios }\end{array}$ & $\begin{array}{c}\text { Participación de las } \\
\text { regalías en el total de } \\
\text { recursos tributarios }\end{array}$ & $\begin{array}{c}\text { Totales ingresos } \\
\text { corrientes }\end{array}$ & $\begin{array}{c}\text { Participación de las } \\
\text { regalías en el total de } \\
\text { ingresos corrientes }\end{array}$ \\
\cline { 2 - 6 } & \$corrientes & \$corrientes & (porcentaje) & \$corrientes & (porcentaje) \\
\hline 2008 & 61.637 .490 & 2.650 .186 .120 & 2,3 & 3.438 .505 .822 & 1,8 \\
\hline 2009 & 56.520 .569 & 3.005 .005 .003 & 1,9 & 3.680 .269 .460 & 1,5 \\
\hline 2010 & 91.850 .000 & 3.205 .126 .000 & 2,9 & 4.052 .588 .000 & 2,3 \\
\hline 2011 & 159.974 .000 & 4.508 .089 .000 & 3,5 & 6.146 .745 .000 & 2,6 \\
\hline 2012 & 278.507 .000 & 6.286 .503 .000 & 4,4 & 7.941 .342 .000 & 3,5 \\
\hline 2013 & 278.027 .000 & 7.981 .850 .000 & 3,5 & 10.012 .167 .000 & 2,8 \\
\hline 2014 & 255.600 .000 & 10.904 .724 .000 & 2,3 & 13.462 .583 .000 & 1,9 \\
\hline 2015 & 299.441 .000 & 15.297 .490 .000 & 2,0 & 18.767 .831 .000 & 1,6 \\
\hline 2016 & 469.681 .378 & 21.138 .294 .350 & 2,2 & 26.782 .198 .747 & 1,8 \\
\hline
\end{tabular}

Fuente: elaboración propia con datos de la Cuenta de Inversión, Gobierno de la Provincia de San Juan (2017).

\subsection{Las retenciones a las exportaciones del complejo sojero}

La aplicación de este tributo 25 a las exportaciones agropecuarias tiene una larga historia en el país, con aplicaciones reiteradas en contextos macroeconómicos diver$\operatorname{sos}^{26}$. Como herramienta de política pública, y desde una perspectiva de mediano y largo plazos, su aplicación produce básicamente dos efectos económicos: aumen-

24 En el año 2013 el precio comenzó a bajar: alcanzó un promedio de U\$ 1650 por onza en ese año; y en 2016, descendió a U\$ 1170.

25 Las retenciones o derechos de exportación son un impuesto a los bienes y servicios exportados.

26 Las retenciones rigieron en el país entre 1862 y 1888; de 1890 a 1905; y de 1918 a 1925. En 1955 y en el periodo 1960 - 2015, se aplicaron en 41 años. (Grasso, 2005, como se citó en Arceo, 2010). 
to de los recursos fiscales a través de la apropiación directa por parte del Estado de una porción del excedente generado en el sector agropecuario; y modificación de la estructura de precios relativos, a partir de lo cual se desvinculan los precios internos frente a los internacionales. Este fenómeno cobra especial relevancia en el caso de las producciones agroalimentarias dado que atenúa el impacto negativo de los ciclos favorables en los mercados internacionales y, de modo más general, provoca una transferencia de recursos al conjunto de la sociedad, en particular a los sectores de consumo popular.

Tabla 8. Relación entre regalías, coparticipación y gastos

\begin{tabular}{|c|c|c|c|c|c|}
\hline \multirow{2}{*}{ Años } & Regalías & $\begin{array}{c}\text { Recursos por } \\
\text { coparticipación }\end{array}$ & $\begin{array}{c}\text { Relación regalías/ } \\
\text { coparticipación }\end{array}$ & Total gastos & $\begin{array}{c}\text { Relación } \\
\text { regalías/gastos }\end{array}$ \\
\cline { 2 - 6 } & $\$$ corrientes & \$corrientes & $\%$ & \$corrientes & $\%$ \\
\hline 2008 & 61.637 .490 & 1.150 .919 .600 & 5,4 & 3.962 .047 .389 & 1,6 \\
\hline 2009 & 56.520 .569 & 1.471 .047 .100 & 3,8 & 4.718 .322 .958 & 1,2 \\
\hline 2010 & 91.850 .000 & 1.525 .474 .000 & 6,0 & 5.360 .722 .000 & 1,7 \\
\hline 2011 & 159.974 .000 & 2.522 .277 .000 & 6,3 & 7.158 .176 .000 & 2,2 \\
\hline 2012 & 278.507 .000 & 3.509 .225 .000 & 7,9 & 10.004 .084 .000 & 2,8 \\
\hline 2013 & 278.027 .000 & 4.346 .090 .000 & 6,4 & 12.666 .450 .000 & 2,2 \\
\hline 2014 & 255.600 .000 & 5.395 .595 .000 & 4,7 & 17.184 .133 .000 & 1,5 \\
\hline 2015 & 299.441 .000 & 7.418 .184 .000 & 4,0 & 21.279 .913 .000 & 1,4 \\
\hline 2016 & 469.681 .378 & 9.462 .299 .000 & 5,0 & 27.499 .957 .000 & 1,7 \\
\hline
\end{tabular}

Fuente: elaboración propia con datos de la Cuenta de Inversión, Gobierno de la Provincia de San Juan (2017).

Las exportaciones de soja, en todas sus variedades y sus derivados, contribuyen desde la sanción de Decreto PEN n. ${ }^{\circ} 206$ de marzo de 2009 a la conformación del Fondo Federal Solidario (FFS), al cual se destina el 30 \% de lo recaudado por el Estado Nacional en concepto de derechos por su venta al exterior. Los datos presentados en la primera sección aproximan el valor de las contribuciones provinciales que, en función de la concentración de la exportación de derivados, tienen un aporte significativo de las provincias pampeanas (Santa Fe, Córdoba y Buenos Aires).

El FFS, expresado en pesos constantes de 1994, después de un crecimiento en el año de inicio ha reducido su magnitud siguiendo el valor de las exportaciones y de la alícuota; y ha pasado de un monto anual cercano a los \$ 19.000 millones en 
2010, a \$ 12.000 millones en 2016. En efecto, la evolución del FFS ha registrado las variaciones de volúmenes exportados y precios en cada periodo, a excepción del año 2016 que recoge, de manera adicional, la reducción de las alícuotas del grano de soja y sus derivados, conforme lo establecido en el Decreto PEN No 133 del 16 de diciembre de $2015^{27}$ (gráfico 1). Cabe esperar la continuidad de la caída, dadas las nuevas reducciones dispuestas para los granos y la eliminación del gravamen a biodiésel para el presente año, y una tendencia decreciente permanente.

\section{Gráfico 1. Evolución del Fondo Federal Solidario, 2010-2016}

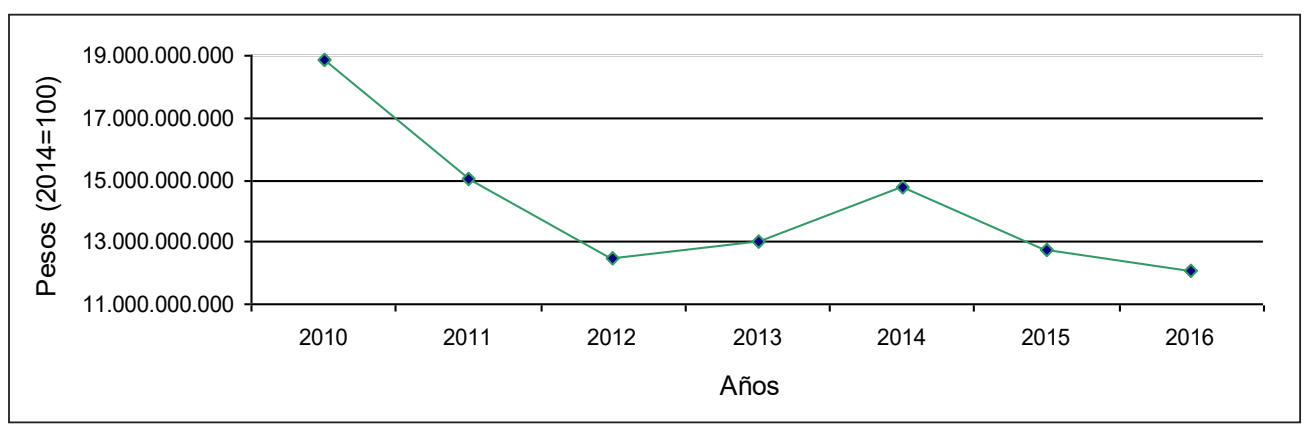

Fuente: elaboración propia con datos del Ministerio de Hacienda (2017).

El Decreto PEN n. 243/09 regula la distribución de los recursos de ese Fondo: establece que esta se realizará según las proporciones establecidas en la Ley de Coparticipación Federal de Recursos Fiscales, de cuya aplicación resulta que la provincia de Buenos Aires recibe el 21,2 \%, Córdoba el 8,58 \% y Santa Fe el 8,63 \% del total recaudado ${ }^{28}$.

La consideración de lo aportado en conjunto al FFS por las exportaciones del grano de soja -alrededor del $81 \%$-y lo recibido - $38,42 \%$ - aproxima evidencia de un intenso proceso de redistribución territorial del excedente generado en la producción primaria del complejo sojero. Una lectura más desagregada permite obser-

27 Esta medida se implementó pocos días después de la asunción del nuevo gobierno. Lo anterior es muestra elocuente de los compromisos asumidos con los sectores del agronegocio en relación con el cambio de rumbo de las retenciones a la exportación, que fue una de las políticas públicas del anterior gobierno que más resistencia y conflictividad desató con dichos actores económicos. Alrededor de esta disputa aparecieron cuestiones centrales referidas a las políticas para aprovechar el "superciclo" en los precios de los commodities (entre ellos los agrícolas), con lo que se atenuaron los impactos negativos de las subas de precios de los alimentos sobre los sectores de menores ingresos y, entre otros objetivos, la potencial redistribución a través de políticas sectoriales y territoriales.

28 Del total destinado a las provincias (el "reparto secundario"), cada una percibe según los coeficientes fijados en la Ley 23.548, dado el cálculo en función de la cantidad de población, densidad y otros indicadores (variables) que han surgido en el marco de las recurrentes tensiones entre nación y provincias, y en las provincias entre sí. 
var que, entre las provincias exportadoras, solo en cinco de ellas se han registrado aportes netos positivos. El resto de las jurisdicciones nacionales son receptoras netas de recursos del Fondo.

Tabla 9. Aportes de soja en grano al Fondo Federal Solidario, año 2016

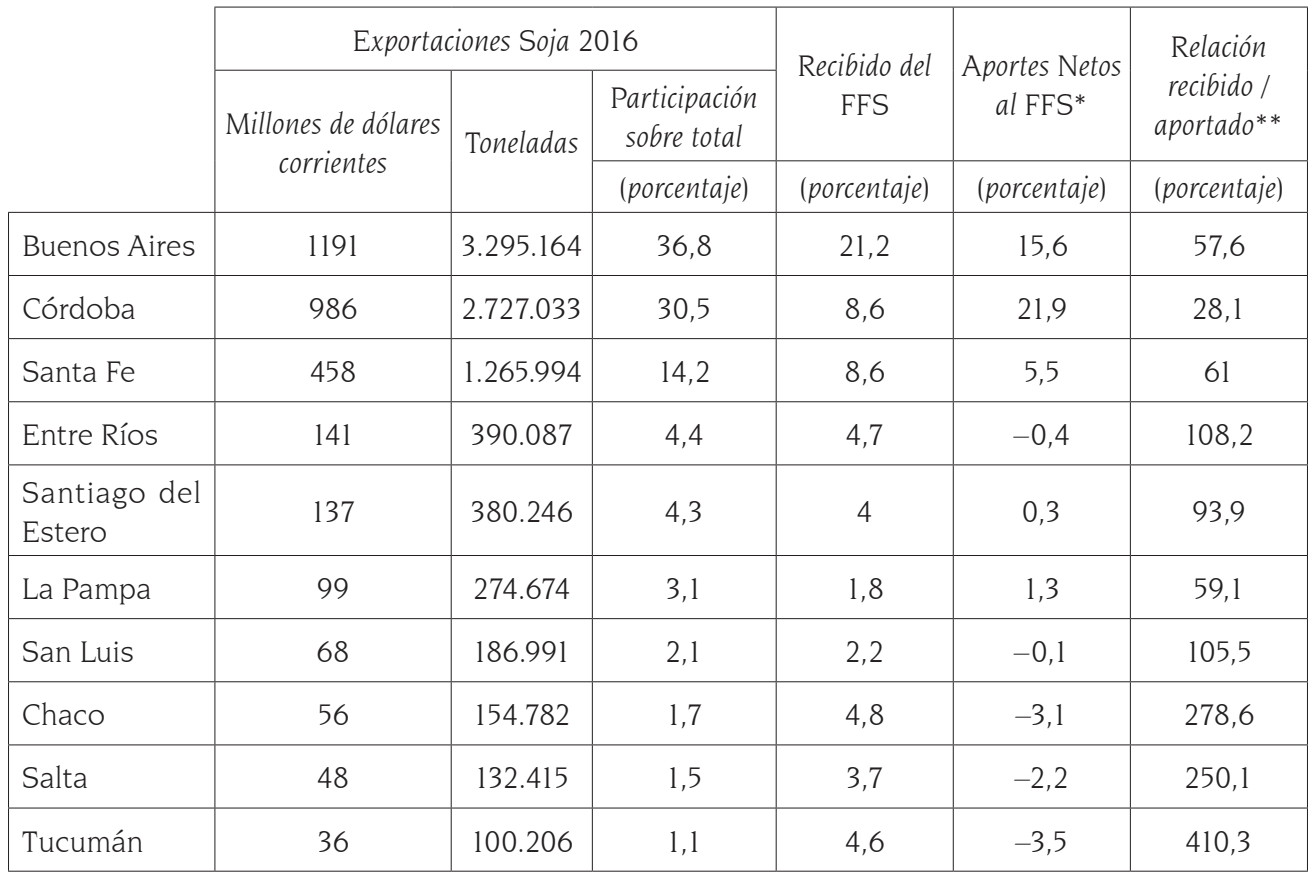

* Participación sobre el total-recibido del FFS. "* Recibido del FFS / participación sobre el total.

Fuente: elaboración propia con datos de OPEX-Indec y Decreto PEN n. ${ }^{\circ}$ 206/2009 (2017).

La tabla 9 muestra que la Provincia de Córdoba es la que más contribuye en términos netos, con casi un $22 \%$ de los recursos totales del Fondo, resultado de recibir solo un $28 \%$ de lo aportado. La provincia de Buenos Aires, que registra el mayor aporte absoluto, realiza una contribución neta menor: recibe un 58 \% de lo aportado. Cabe recordar que este reparto replica las alícuotas establecidas en la ley de coparticipación federal, por la cual la primera percibe porcentajes que más que duplican al de la segunda.

Los productos manufacturados del grano de soja exportables son alcanzados también por los derechos de exportación ${ }^{29}$ que alimentan el FFS y modifican los aportes relativos provinciales. Como se muestra en la tabla 10, las provincias

\footnotetext{
29 Se han considerado tasas del $30 \%$ para el grano, del $32 \%$ para el biodiesel y del $27 \%$ para los productos
} restantes. 
de Córdoba y, fundamentalmente, Santa Fe, realizan un aporte neto al FFS; ello refleja, además de las alícuotas ya mencionadas, la concentración espacial de las exportaciones del complejo sojero derivadas de la renta de posición geográfica (puerto), lo mismo que las ventajas de localización por la dotación de infraestructuras, en general construidas con cargo al colectivo de la sociedad nacional.

Tabla 10. Fondo Federal Solidario, distribución provincial

\begin{tabular}{|l|c|c|c|c|}
\cline { 2 - 5 } \multicolumn{1}{c|}{} & $\begin{array}{c}\text { Aportes } \\
\text { (porcentaje) }\end{array}$ & $\begin{array}{c}\text { Recibido } \\
\text { (porcentaje) }\end{array}$ & $\begin{array}{c}\text { Aportes netos } \\
\text { al FFS } \\
\text { (porcentaje) }\end{array}$ & $\begin{array}{c}\text { Relación recibido }) \\
\text { aportado } \\
\text { (porcentaje) }\end{array}$ \\
\hline Buenos Aires & 17,77 & 21,21 & $-3,44$ & 119,4 \\
\hline Chaco & 0,21 & 4,82 & $-4,61$ & $2.345,10$ \\
\hline Córdoba & 20,53 & 8,58 & 11,95 & 41,8 \\
\hline Entre Ríos & 0,52 & 4,72 & $-4,2$ & 911,2 \\
\hline La Pampa & 0,36 & 1,81 & $-1,45$ & 496,3 \\
\hline Salta & 0,18 & 3,7 & $-3,52$ & $2.104,30$ \\
\hline San Luis & 0,25 & 2,2 & $-1,95$ & 886 \\
\hline Santa Fe & 58,86 & 8,63 & 50,23 & 14,7 \\
\hline S. del Estero & 0,51 & 3,99 & $-3,48$ & 790 \\
\hline Tucumán & 0,13 & 4,59 & $-4,46$ & $3.449,50$ \\
\hline Indeterminado & 0,69 & 0 & 0,69 & 0 \\
\hline Total & 100 & 64,25 & 35,75 & 64,25 \\
\hline
\end{tabular}

Fuente: elaboración propia con datos de OPEX-Indec y Decreto PEN n. 206/2009 (2017).

La distribución del FFS ha impactado de manera diferencial en las provincias argentinas. La información registrada ilustra los impactos fiscales y las magnitudes relativas por persona. La tabla 11 expresa de forma elocuente las diferentes contribuciones jurisdiccionales: en Santiago del Estero, por ejemplo, el aporte del FFS como proporción de los ingresos corrientes es 8 veces mayor que el de CABA. La reducción presentada en el gráfico 1 ha implicado una caída en su relevancia sobre el total de los recursos presupuestarios provinciales, hecho que se demuestra en los valores contenidos en la siguiente tabla. 
Tabla 11. Relación del Fondo Federal Solidario con los Ingresos Corrientes de Administración Central Provincial, año 2016

\begin{tabular}{|l|c|l|c|}
\hline \multicolumn{1}{|c|}{ Provincia } & Porcentaje & \multicolumn{1}{|c|}{ Provincia } & Porcentaje \\
\hline Santiago del Estero & 3,60 & Misiones & 2,61 \\
\hline Catamarca & 3,44 & Río Negro* & 2,58 \\
\hline Formosa & 3,37 & Tucumán & 2,39 \\
\hline Corrientes & 3,36 & Santa Fe & 2,35 \\
\hline La Rioja* & 3,22 & La Pampa* & 2,27 \\
\hline Chaco & 3,06 & Tierra del Fuego & 1,94 \\
\hline San Juan & 3,02 & Santa Cruz** & 1,85 \\
\hline San Luis & 3,01 & Chubut*** & 1,79 \\
\hline Jujuy & 2,82 & Buenos Aires & 1,63 \\
\hline Entre Ríos* & 2,82 & Mendoza & 1,46 \\
\hline Salta & 2,69 & Neuquén & 1,23 \\
\hline Córdoba & 2,63 & CABA & 0,44 \\
\hline
\end{tabular}

* Año 2015. ** Año 2014. *** Año 2011.

Fuente: elaboración propia con datos del Ministerio de Economía de la Nación.

La distribución per cápita también muestra (tabla 12) valores que indican una fuerte redistribución territorial de los recursos del FFS. Así, encontramos que lo percibido por cada poblador fueguino es casi 900 \% más de lo que percibe un residente en la CABA.

La redistribución de los recursos provenientes de las exportaciones del complejo sojero, sin embargo, no parece haber contribuido a reducir disparidades territoriales preexistentes. En efecto, desde el plano estadístico no se han encontrado correlaciones significativas ${ }^{30}$ entre niveles de pobreza e indigencia y las asignaciones per cápita del FFS, aunque se registra una correlación negativa y débil entre esta variable y el índice de desarrollo sostenible provincial (IDSP). En tanto, la contribución del FFS a los presupuestos provinciales como proporción de los ingresos corrientes muestra una correlación positiva con la pobreza, con una significatividad estadística débil; mientras que no se observan correlaciones significativas entre el FFS per cápita y la indigencia o el IDSP. Se analizaron coeficientes de correlación simples y ajustes tendenciales, lineales y no lineales con
ordenada al origen estimados por MCO. 
Silvia Gorenstein - Jorge Hernández - Delia De La Torre

Tabla 12. Distribución del Fondo Federal Solidario per cápita, año 2016

\begin{tabular}{|l|c|l|l|}
\hline \multicolumn{1}{|c|}{ Provincia } & \multicolumn{1}{c|}{$\mathbf{S *}^{*}$} & \multicolumn{1}{|c|}{ Provincia } & \$* \\
\hline Tierra del Fuego & 919,6 & Río Negro & 415,5 \\
\hline Catamarca & 802,3 & Corrientes & 401,6 \\
\hline Formosa & 726,8 & Tucumán & 344,2 \\
\hline La Rioja & 648,2 & Salta & 330,9 \\
\hline La Pampa & 633,2 & Neuquén & 322,1 \\
\hline Santa Cruz & 560,4 & Misiones & 320,2 \\
\hline San Luis & 551,9 & Chubut & 319,8 \\
\hline San Juan & 527,9 & Santa Fe & 304,5 \\
\hline Santiago del Estero & 514,1 & Córdoba & 287,4 \\
\hline Chaco & 503,9 & Mendoza & 255,3 \\
\hline Jujuy & 450,2 & Buenos Aires & 152,2 \\
\hline Entre Ríos & 427,1 & CABA & 94,1 \\
\hline
\end{tabular}

* Moneda argentina de 2014.

Fuente: elaboración propia con datos de Indec (2017).

Estos resultados no invalidan este tipo de medidas de política pública. Más allá de la relatividad de las cifras que se reparten -el FFS recoge solo el $30 \%$ de los ingresos generados por las exportaciones, frente al 70\% restante de las asignaciones discrecionales del Ejecutivo Nacional-, el potencial distributivo justifica su existencia y desafía la elaboración de dispositivos complementarios que tiendan a ello en el marco de políticas multiescalares de mediano y largo plazo que se combinen con estos recursos. En definitiva, la posibilidad de capturar y distribuir las rentas generadas (desde los puntos de vista social y territorial) en actividades intensivas en recursos naturales, exige institucionalizar el proceso. Por ello, es necesario construir los acuerdos sociales y los consensos políticos necesarios para que los Estados puedan canalizar estas rentas hacia inversiones u otras medidas orientadas al desarrollo territorial sostenible e inclusivo.

\section{CONCLUSIONES}

Este trabajo ha avanzado en la identificación de algunos impactos territoriales producidos por la minería y las actividades vinculadas al complejo sojero. Una de las conclusiones más visibles remite a la existencia de ciertas reconfiguraciones produc- 
tivas, impulsadas por las tendencias reprimarizantes y sus traducciones a la luz de las dinámicas que exhiben $\mathrm{CPG}$, o bien que se encuentran sometidas a esta lógica.

La intensificación de la actividad minera y la expansión geográfica del complejo sojero, que ha adoptado los rasgos típicos del agronegocio pampeano, se produjeron en un periodo en el que la demanda internacional de diversos sectores primarios acusó un aumento significativo. Ello determinó niveles elevados de precios que permitieron la emergencia de rentas relativas crecientes, provenientes de especificidades territoriales (existencias de yacimientos, condiciones agroecológicas especiales y ventajas de posición) e infraestructuras preexistentes ${ }^{31}$. Por su parte, hubo cambios en la regulación, en particular para la minería y biocombustibles durante la década de 1990 e inicios del 2000, que antecedieron al superciclo de los commodities, lo que ha generado un contexto favorable para los grandes inversores -en particular, transnacionales-.

En el proceso expansivo de las dos producciones analizadas se pueden identificar, de forma estilizada, los siguientes rasgos:

- Estructuras productivas de provincias extrapampeanas atravesadas por las transformaciones (sociales, económicas y espaciales) que devienen de la implantación del modelo pampeano de agricultura extensiva, en especial soja; en cambio, los segmentos manufactureros de este complejo profundizaron su concentración en las provincias pampeanas, principalmente en Santa Fe. De manera simultánea, se observa la reespecialización productiva de la provincia de San Juan, expresada en el cambio de su base de exportación con el valor de las ventas al exterior de la minería metalífera, que desplaza las tradicionales (agrícolas).

- Dadas las características funcionales de estos sectores productivos, sumados a los cambios tecnológicos y organizacionales incorporados, no se han generado efectos cuantitativos intensos en las estructuras locales de empleo; en cambio, sí se han presentado alteraciones cualitativas de consideración. Por un lado, las repercusiones laborales de la agricultura pampeanizada, con indicadores de productividad más altos y bajísima elasticidad empleo-producto, se manifiestan en reducciones de la fuerza de trabajo ocupada, acortamiento de los tiempos de trabajo y cambios en la relación laboral, lo cual acarrea una intensificación de la tendencia a la tercerización y la contratación de mano de obra temporal. En la minería metalífera, por su parte, el dinamismo exhibido en la etapa de construcción contrasta con la baja intensidad de la demanda de empleo al comenzar el funcionamiento de las minas. No obstante, este tiene una notable repercu-

31 La salida del sistema monetario convertible adicionó un impulso derivado de la devaluación de la moneda argentina. 
sión en la estructura local de salarios, mucho más altos, y por las condiciones de empleo registrado.

Con el crecimiento de las rentas relativas en territorios pampeanos -beneficiados por la particular inserción argentina en el mercado internacional-, y su incipiente derrame a nuevos territorios, se produjo también, como contra cara, una estrategia redistributiva a través de la implementación de una herramienta de política pública.

En este trabajo se ha analizado la aplicación de las retenciones al Fondo Federal Solidario; si bien solo se han considerado los montos monetarios asignados entre las provincias ${ }^{32}$, su escaso y decreciente volumen no desmerece el efecto redistributivo ni la posibilidad de acompañarlo con otras estrategias de mediano y largo plazo, que conduzcan y mejoren la apropiación colectiva de rentas relativas derivadas de actividades intensivas en recursos naturales. Su eliminación no solo deterioraría las actuales condiciones, sino que profundizaría las repercusiones negativas derivadas de las dinámicas que imprimen actores (extralocales o no), expresadas en fugas hacia otros territorios (nacional, global) de los ingresos generados en cada una de las regiones; $y$ en el crecimiento de inversiones inmobiliarias en lugar de su aplicación en actividades que generen incremento en el valor agregado y diversificación productiva.

En mayor o menor medida, los efectos anteriores se replican en el caso del complejo minero sanjuanino que, a su vez, no ofrece evidencia de un aporte significativo a través de los recursos apropiados en el presupuesto del gobierno provincial. El mecanismo de determinación de la base imponible -volumen de facturación de la mina-ilustra la subordinación del poder político local al interés del capital privado. En esta misma dirección, se observa que el complejo sojero ha podido conseguir ventajas impositivas provinciales notables, en la medida en que la base imponible de los impuestos inmobiliarios rurales se ha desactualizado en términos reales: sube menos que la inflación y no contempla el incremento de valores de cambio, que casi se han duplicado33.

Además de evidenciar la escasa capacidad de los estados provinciales para imponer tributos progresivos, el deterioro de los activos locales da cuenta de la necesidad de intervenciones de doble carácter (nacional/provincial), en tanto que

32 No se han considerado acciones como la asignación diferencial de infraestructuras (red vial, acceso a servicios básicos -sanitarios, de salud, etc.-, y de modernización - informatización, I+D-.), equipamiento (escuelas, hospitales, etc.) y rentas monetarias.

33 Esto se verifica, además, con la pérdida de participación relativa de estos impuestos en la estructura de ingresos de los estados provinciales. 
asume la inexistente convergencia a través de mecanismos de mercado para mejorar las condiciones socioproductivas territoriales. En este sentido, los derechos de exportación, o retenciones, pueden definir un escenario de negociación y control entre el Estado Nacional y las empresas exportadoras que, según la orientación y voluntad política, elevan la objetivación de la base de tributación y con ello pueden mejorar la eficiencia recaudatoria; a la vez que, asignados con corrección por el lado del gasto público, pueden convertirse en eficaces vectores de reducción de las disparidades.

\section{BIBLIOGRAFÍA}

Aguirre Unceta, R. (2017). Recursos naturales y desarrollo: los dilemas de una relación crítica. En: Documento de Trabajo n. ${ }^{\circ}$ 39, Instituto Universitario de Desarrollo y Cooperación (IUDC). Madrid: Universidad Complutense de Madrid, 100p.

Altomonte, H. y Sánchez, R. J. (2016). Hacia una nueva gobernanza de los recursos naturales en América Latina y el Caribe, Libros de la Cepal n. 139 (LC/G.2679-P). Santiago de Chile: Cepal, 258p.

Arceo, N. (2010). El rol del sector agropecuario pampeano en la economía argentina. 1958-2007. Tesis para optar al título de doctor en ciencias sociales. Doctorado en Ciencias Sociales, Flacso, Buenos Aires, 220p.

Basualdo, F. (2012). Desempeño de la actividad minera metalífera en la Argentina. Renta minera y distribución de los beneficios. En: Apuntes para el Cambio, n.ㄹ 2 marzo-abril, p. 1-15.

Bisang, R. y Sztulwark, S. (2007). Tramas productivas de alta tecnología y ocupación. El caso de la soja transgénica en Argentina. En: Estructura productiva y empleo. Un enfoque transversal. Buenos Aires: Miño y Dávila Editores, Ministerio de Trabajo, Empleo y Seguridad Social, 47p.

CAME -Cámara Argentina de Empresarios Mineros- (2016). Reposición de retenciones. Impacto social y fiscal, industria minera. San Juan, Argentina: CAME, 38p.

Cifra -Centro de Investigación y Formación de la República Argentina- (2011). El nuevo patrón de crecimiento. Argentina 2002-2010. En: Informe de Coyuntura, n. ${ }^{\circ}$ 7, mayo, 38p.

Daher A.; Moreno D. y Aninat M. (2017). Efectos socioterritoriales en Chile del súper ciclo de los commodities y de su término. En: Caderno Metropoli, Sao Paulo, Vol. 19. n. ${ }^{\circ} 38$, enero-abril 2017, p.127-155.

Daher, A. (2003). Regiones-commodities. Crisis y contagio en Chile. En: EURE vol. 29, n. ${ }^{\circ}$ 86; p. 89- 108.

Donadoni, M.; Castro, M.; Natali, P., Emiliozzi, A. y Hernández J. (2017). Biocombustibles y territorio. Una aproximación al interior pampeano. Working paper en Jornada de Desarrollo Local Regional: "Desarrollo Local: Debate en torno al perfil productivo del país". VII Reunión Anual de la Sociedad Argentina de Economía Regional (SAER). Villa María, Córdoba, agosto de 2017. 
Gatto, F. (2013). Algunos elementos claves en el diseño de estrategias territoriales de equidad e inclusión productiva y social en la Argentina. En Infante R. y Gerstenfeld P. Hacia un desarrollo inclusivo. El caso de la Argentina. Buenos Aires: Cepal-OIT, 267p.

Gorenstein, S. (2016). Empresas transnacionales en la agricultura y la producción de alimentos en América Latina y el Caribe. En: Fundación Foro Nueva Sociedad (NUSO). Documento de Trabajo. Buenos Aires: Fundación Foro Nueva Sociedad (NUSO), 30p.

Gorenstein S.; Schorr M. y Echeverría E. (2012). Complejos productivos con encadenamientos industriales en el norte argentino: algodón, azúcar y yerba mate. En Gorenstein, S. (Org.). ¿Crecimiento o desarrollo? El ciclo reciente en el norte argentino (p. 55-84). Buenos Aires: Miño y Dávila.

Hirschman, A. O. (1958). The Strategy of Economic Development. New Haven: Yale University Press, 217p.

Hirschman, A. O. (1977). A Generalized Linkage Approach to Development, with Special Reference to Staples. En: Essays on Economic Development and Cultural Change: In Honor of Bert F. Hoselitz (p. 67-98). Chicago: University of Chicago Press.

Lódola, A. y Fossati, R. (2004). Servicios agropecuarios y contratistas en la provincia de Buenos Aires, Working Paper. Asociación Argentina de Economía Política, 24p.

Marchegiani, P. y Di Paola, M. (2017). La minería en la tierra de plata ¿política minera o mineras que (trans)forman la política? Buenos Aires: Fundación Ambiente y Recursos Naturales (FARN), 38p.

Ministerios de Hacienda y Finanzas Públicas de la Nación (2016). Minería metalífera y rocas de aplicación en Argentina. En: Informes de Cadena de Valor, Año 1, n. 2, p. 64.

Neiman, G. (Ed.) (2010). Estudios sobre la demanda de trabajo en el agro argentino. Buenos Aires: Ediciones Ciccus, 250p.

Palmieri, Pilar (2012). Fiscalidad y minería en la Argentina: el caso de la renta del oro en el marco de la crisis financiera internacional. En: Voces en el Fénix. Año 2, n. 14, p. 46-53.

Universidad Nacional Tecnológica (s. f.). Desarrollo Socioeconómico de la Provincia de San Juan. Impacto de la Mina Veladero. San Juan: Universidad Nacional Tecnológica, 66p.

Vidosa, Regina (2017). Régimen sectorial de funcionamiento en la cadena de soja: inserción internacional, formas de competencias, políticas monetarias y relación salarial, en el periodo 2002-2015, Tesis para optar al título de Magíster en Economía Política con mención en Economía Argentina, Flacso, Buenos Aires. 